\title{
ANOMALOUS PREFERENCES OF CULTURED MACROPHAGES FOR HYDROPHOBIC AND ROUGHENED SUBSTRATA
}

\author{
ABBY RICH* AND ALBERT K. HARRIS \\ Department of Zoology, University of North Carolina, Chapel Hill, N.C. \\ 275 I 4, U.S.A.
}

\section{SUMMARY}

Peritoneal macrophages were plated out on a series of artificial haptotactic substrata consisting of grid patterns of vacuum-evaporated palladium metal alternating with hydrophobic untreated polystyrene and with hydrophilic sulphonated polystyrene. By their active locomotion the macrophages accumulated preferentially onto the less hydrophilic of either pair of these alternative substrata. This order of substratum preference is precisely the opposite to that shown by fibroblastic cells. Macrophages were also found to accumulate preferentially onto roughened culture surfaces as opposed to smooth ones, which is again opposite to the behaviour of fibroblasts. These opposite substratum preferences shown by macrophages may reflect physical as well as functional differences in their surfaces, and could serve as assay criteria for macrophages and cell types putatively equivalent to macrophages.

\section{INTRODUCTION}

Tissue-cell locamotion requires a substratum and the properties of this substratum can strongly influence the locomotion that occurs. For example, Carter (1967a,b) showed that fibroblasts migrate preferentially from cellulose acetate to thin vacuumevaporated layers of palladium metal. In a later study (Harris, 1973), both normal and transformed fibroblasts were found to migrate onto sulphonated polystyrene (as well as onto glass in preference to palladium, but onto palladium in preference to untreated polystyrene).

In each of these cases the cells showed a consistent hierarchy of relative adhesive preference, accumulating on the more hydrophilic of any pair of substances. More recently, Letourneau (1975) showed that nerve growth cones obey this same hierarchy of substratum preference and can be guided along paths of greater adhesiveness. This demonstration lends support to theories of nerve guidance by adhesive differences (Barbera, Marchase \& Roth, I973).

In those previous studies, each cell type showed the same sequence of relative preference for substrata. We have now studied the adhesive preferences of the macrophage, a cell type whose behaviour was already known to be unusual in several respects. Macrophages migrate invasively as part of their normal function, fail to show contact inhibition of locomotion (Oldfield, 1963), and even show a sort of

- Present address : Department of Cell Biology, New York University Medical Center, New York, N.Y. 10016, U.S.A. 
reverse contact inhibition relative to fibroblasts (Harris, 1974). We have found that macrophages also show significant differences in their adhesive preferences.

\section{MATERIALS AND METHODS}

Peritoneal macrophages were obtained from Swiss white mice, which were killed by cervical dislocation and the cells collected in $3-4 \mathrm{ml}$ of phosphate buffered saline (PBS) (Dulbecco \& Vogt, 1954). In some experiments, heparin was included in the saline, but seemed to make no difference to the results. After centrifugation, the cells were resuspended in PBS and allowed to settle onto the experimental substrata for $15-20 \mathrm{~min}$ at $37^{\circ} \mathrm{C}$, before replacing the saline with Dulbecco's modified Eagles medium buffered with 25 mM- $N$-2-hydroxyethylpiperazine$N^{\prime}$-ethanesulfonic acid (HEPES), and supplemented with $10 \%$ foetal calf serum (GIBCO, Grand Island, N.Y.) and penicillin and streptomycin. For certain experiments, $5 \mathrm{ml}$ of thioglycollate medium (Fisher Scientific Co.) was injected intraperitoneally 5 days prior to collecting macrophages as above. A culture of the macrophage-like cell line, $\mathrm{P}_{33} 8 \mathrm{D}_{1}$, was a gift from Dr H. S. Koren, Duke University. WI 38 cells, VAI 3 cells (a line of untransformed fibroblasts), simian virus-transformed VAI 3 cells, and L929 cells (a transformed line of mouse fibroblasts) were all obtained from the Tissue Culture Laboratory, Cancer Research Center, University of North Carolina at Chapel Hill. H6r 5 ts $3^{\text {T }} \mathbf{3}$ cells were a generous gift from Dr Kenneth Noonan of the University of Florida.

Three artificial substrata were used: ( $\mathrm{r}$ ) untreated polystyrene dishes, $35 \mathrm{~mm}$ in diameter; (2) polystyrene dishes treated with concentrated sulphuric acid for $2 \mathrm{~h}$ to make the substratum hydrophilic (Maroudas, I975); and (3) palladium evaporated onto treated and untreated polystyrene (Carter, $1967 b$ ). All 3 of these culture surfaces could be produced side-by-side in individual Petri dishes. Approximately $2 \times 10^{5}$ macrophages were plated on 1 dish.

Slightly roughened regions were created on Falconized polystyrene surfaces of tissue culture flasks by gently sliding the round, fire-polished end of a glass rod across the surface so that the rough areas were just barely visible by phase-contract microscopy. Approximately $2 \times 10^{8}$ cells were plated per $25 \mathrm{~cm}^{2}$ flask.

Cultures were viewed with an Olympus $\mathrm{CK}$ inverted phase-contrast microscope and photographed with an Olympus $35 \mathrm{~mm}$ camera using Kodak Panatomic X film. Individual frames from a $16 \mathrm{~mm}$ Bolex camera using Plus $\mathrm{X}$ reversal film were converted to 120 film by a Testrite cine-enlarger. During observations, a Sage air-current incubator maintained the temperature of the cultures at $37^{\circ} \mathrm{C}$.

\section{RESULTS}

When plated out on grid patterns of alternative substrata, both the transformed (VAI3 and $\mathrm{L}_{929}$ ) and untransformed (WI 38 and ts $3 \mathrm{~T}_{3}$ ) fibroblasts migrated preferentially onto the more hydrophilic material available to them (i.e. untreated polystyrene $<$ palladium < sulphonated polystyrene). Peritoneal macrophages, however, developed the opposite sequence of relative preference to these 3 substrata.

Macrophages accumulated on untreated polystyrene in preference to palladium and on palladium in preference to sulphonated polystyrene (Fig. I C, D). In addition, a greater percentage of macrophages flattened themselves onto the more preferred substrata. This reversed pattern of accumulation occurred when foetal calf serum or beef heart infusion was used to supplement the medium.

Another unusual characteristic of macrophages is the length of time required for these reversed-substratum preferences to develop. Fibroblasts accumulated on their preferred substrata within I day but macrophages required between $I$ and 2 days 
to accumulate onto palladium in preference to sulphonated polystyrene, and 7 days to develop their preference for untreated polystyrene over palladium. This delay could not be explained by an insufficient amount of cell locomotion. Time-lapse films showed that the macrophages moved extensively during this 7 -day delay.

To test whether this delay might be caused by a gradual deposition of some secretory product, macrophages were cultured for 2 weeks on one of the untreated polystyrene-palladium substrata and then removed with $4 \%$ EDTA. Fresh macrophages
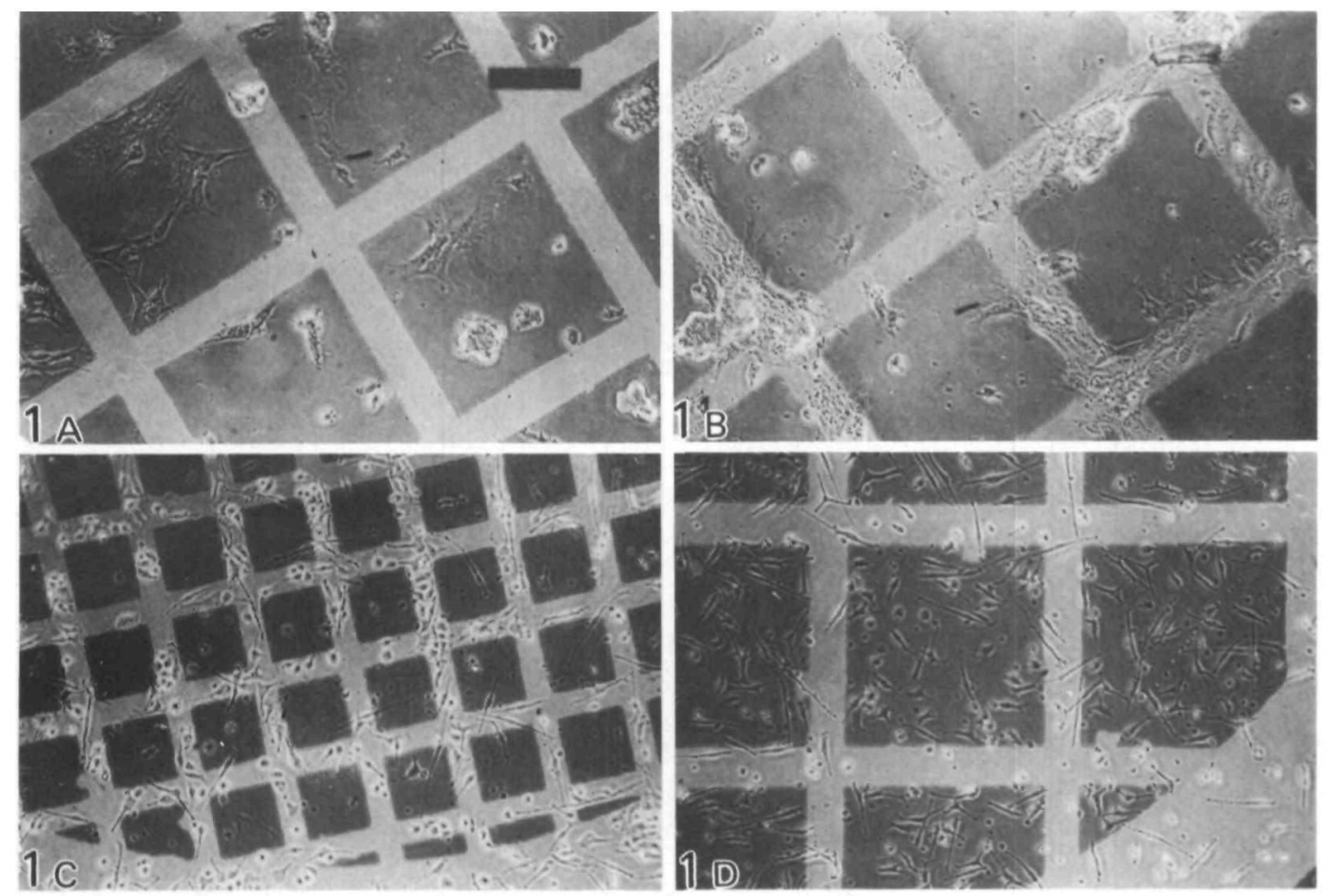

Fig. I. A. Accumulation of ts $3 T_{3}$ fibroblasts on palladium (dark squares) in preference to untreated polystyrene; and $B$, on sulphonated polystyrene in preference to palladium (dark squares). C, Accumulation of macrophages after 7 days in culture on untreated polystyrene in preference to palladium (dark squares); and $\mathrm{D}$, on palladium (dark squares) in preference to sulphonated polystyrene. Bar, O. I mm.

were then plated onto the previously occupied substratum, and they also required 7 days to develop their preference for the more hydrophobic surface. This result shows that whatever change occurs is intrinsic to the cells. In addition, $V_{A_{1}} 3$ fibroblasts were plated out on the same substrata with macrophages and still showed the same sequence of relative preference.

We also considered whether the change in macrophage substratum preference might be related to the set of reactions they can undergo, known as activation. To test the possibility, macrophages were pre-stimulated by an intraperitoneal injection of thioglycollate medium. These macrophages did spread faster than normal ones but 
still required 6 days to accumulate on untreated (hydrophobic) polystyrene in preference to palladium.

We also compared the responses of macrophages and fibroblasts to the roughness or smoothness of their polystyrene substrata. Roughened areas of substratum were strongly shunned by $\mathrm{WI}_{3} 8$ cells as well as $\mathrm{VA}_{1} 3$ and $\mathrm{L}_{929}$ all of which behaved as if they were nearly unable to attach to these areas of rough polystyrene. For convenience we shall call this pattern of behaviour rugophobia (rugo, rough; phobia, fear). Fibroblasts of the ts $3 \mathrm{~T}_{3}$ line readily spread onto the roughened areas, however, and were more or less oblivious to them.

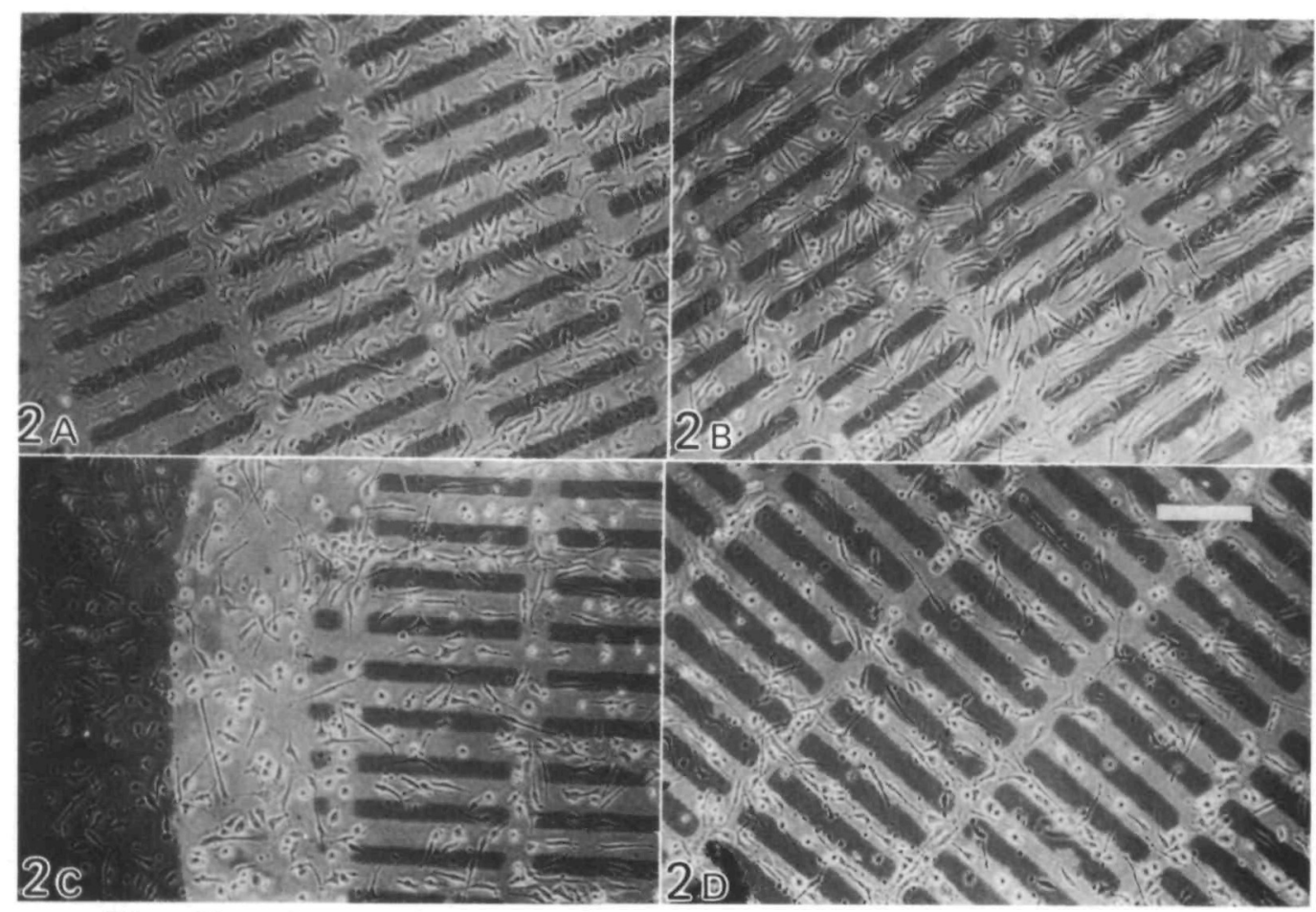

Fig. 2. Normal macrophages on untreated polystyrene and palladium (dark rectangles). $A, I$ day in culture; $B, 4$ days; C, 7 days; D, 9 days. Bar, $0.1 \mathrm{~mm}$.

The response of macrophages to the roughened surfaces was quite different from that of fibroblasts. Macrophages preferentially accumulate on the roughened areas (rugophilia) rather than being unable to spread on them. This property is acquired after 7 days in culture, however; freshly plated macrophages migrate indiscriminately across rough and smooth areas alike. This 7 -day delay was still required even when the macrophages were taken from mice previously injected with thioglycollate. The same pattern of behaviour occurred whether the medium was supplemented with beef heart infusion or with foetal calf serum.

We considered the possibility that our method of roughening the plastic surface might be removing some coating layer, and that these cellular responses might reflect 

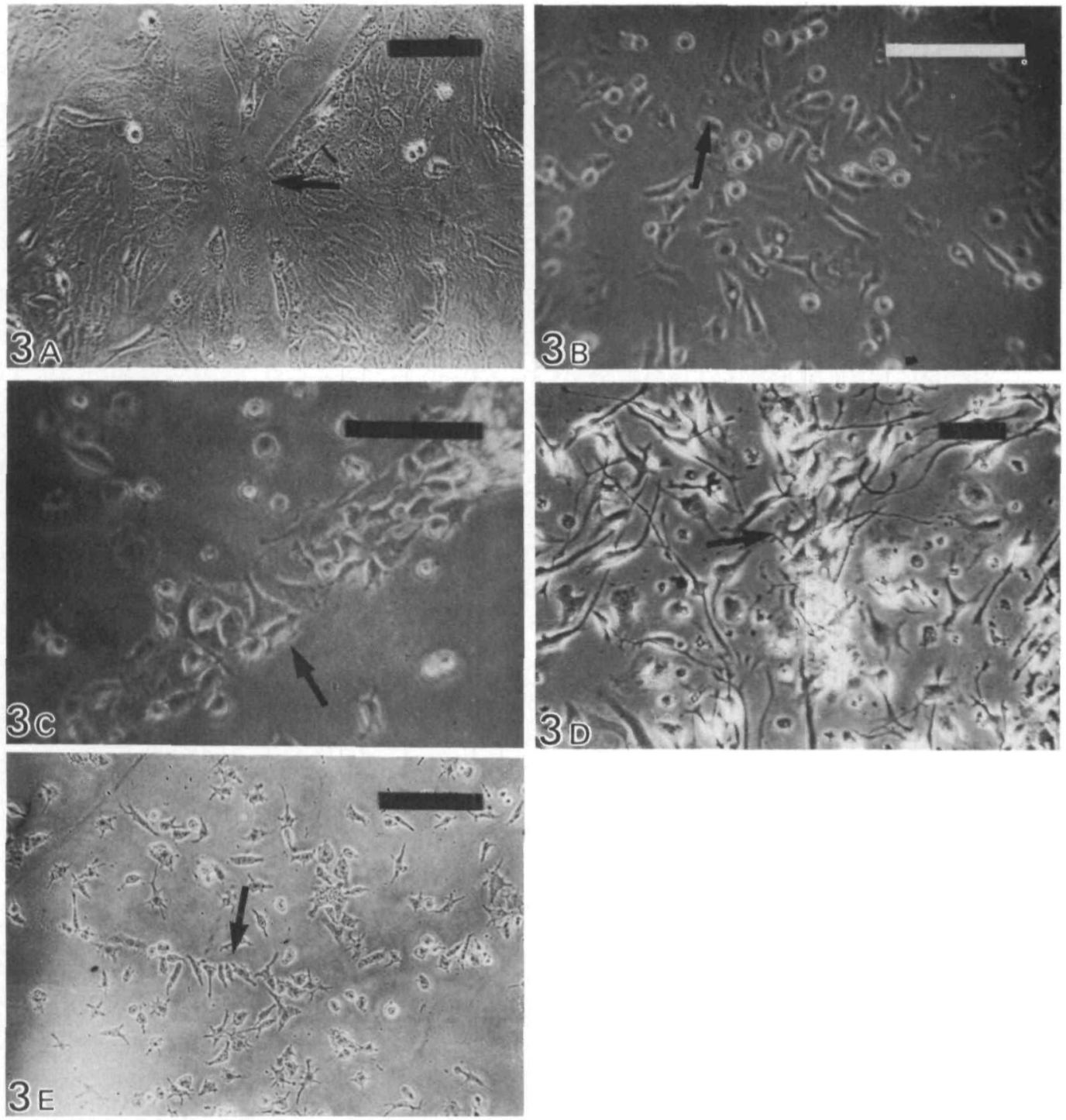

Fig. 3. Cells on rough and smooth falconized polystyrene. Arrows point to roughened area of substrate. Bar, $0_{1} 1 \mathrm{~mm}$. A. Fibroblasts (VAI 3 ). B. Normal peritoneal macrophages after 4 days in culture. C. Normal peritoneal macrophages after 7 days in culture. D. Thioglycollate-stimulated macrophages after 7 days in culture. E. Cells of activatedlike cell line, $\mathrm{P}_{3} 88 \mathrm{D}_{1}$ after 2 days in culture.

the absence of this layer rather than the property of roughness. However, we found that cells responded in the same way to areas roughened on untreated polystyrene as well as to areas that had been sulphonated after roughening.

We also/studied the substratum preferences of $\mathrm{P}_{3} 88 \mathrm{D}_{1}$ cells, a line of cells that closely resemble macrophages both morphologically and biochemically (Koren, Handwerger \& Wunderlich, 1975). These turned out to behave like fibroblasts in that they accumulated preferentially on the more hydrophilic substrata (e.g. sulphonated 
polystyrene in preference to palladium). On the other hand, these $\mathrm{P}_{3} 88 \mathrm{D}_{1}$ cells did accumulate on roughened in preference to smooth surfaces.

\section{DISCUSSION}

We have found that macrophages differ from fibroblasts in their locomotory responses to the chemical and textural properties of artificial culture substrata. The principal differences are as follows.

(I) Macrophages migrate preferentially onto more hydrophobic substrata while fibroblasts accumulate on those that are hydrophilic.

(2) Macrophages accumulate on rough surfaces in preference to smooth ones, while fibroblasts do the reverse.

(3) Macrophages acquire certain of these substratum preferences gradually, while fibroblast preferences remained consistent.

It is unclear what causal linkage may exist between the rugophilia of macrophages and their preference for hydrophobic surfaces. We have experimentally excluded the possibility that roughening the polystyrene merely acts to make it hydrophobic by removing a wettable surface layer. Both these substratum preferences were developed over the same 7 -day delay period, however, which seems to imply some linkage. On the other hand, the cells of the macrophage-like line showed one anomalous property without the other. They were like explanted macrophages in accumulating on roughened areas but resembled fibroblasts in preferring hydrophilic substrata. So the properties can be possessed separately. Perhaps culturing cells of this line for years on wettable surfaces has selected for this hydrophilic preference.

What physical or chemical differences in cellular properties could explain these differing substratum preferences? The contrasting responses to surface roughness could possibly result from differences in cell-surface flexibility. Chambers \& Fell (193I) determined by micromanipulation that macrophage surfaces were unusually pliable and deformable relative to other cell types. On a rough substratum a cell whose own surface is rigid will only be able to touch the substratum at a few peaks. Greater flexibility would permit a cell to extend its surface down into the crevices of the roughened area, permitting it to adhere over a much broader area. Recent observations by Dunn \& Heath (1976) suggest that the bending of cortical microfilaments on curved and grooved substrata plays a casual role in contact guidance. It is important not to confuse the rugophilia of macrophages with contact guidance, however, even though both properties may cause macrophages to align along scratches. One difference is that macrophages accumulate without alignment in broad areas of roughness and another difference is that fibroblasts show contact guidance even though they strongly avoid roughened surfaces.

There are two possible kinds of explanation for the reversed preference of macrophages for hydrophobic instead of hydrophilic substrata. One possibility is that the surface chemistry of macrophages becomes sufficiently different from that of other cells so that it actually forms stronger adhesions to hydrophobic materials than to more wettable ones. An alternative possibility that we considered is that contact with 
hydrophobic surfaces could stimulate directional locomotion in much the same way as diffusible chemotactic attractants. Macrophages are subject to chemotaxis, and Wilkinson (1977) has shown that denatured proteins serve non-specifically as attractants for granulocytes.

To test these possibilities, centrifugation has been used to compare the breaking strength of the adhesions between macrophages and fibroblasts and these artificial substrata. Initial results (Rich, 1978 , and unpublished) indicate that the macrophages actually do develop stronger adhesions to the hydrophobic substrata.

Parts of this work were submitted by A. R. to the Department of Zoology, University of North Carolina, in partial fulfillment of the requirements of the degree of Doctor of Philosophy. The investigation was supported by grants I-RoI-GM23251-OI from the Institute of General Medical Sciences, National Institute of Health, and IN-I5Q from the American Cancer Society and University Research Council, University of North Carolina, Chapel Hill, to A.K.H.

We wish to thank Patricia Wild, E. D. Salmon and M. Rabinovitch for their technical assistance.

This work was prepared for publication at New York University Medical Center, New York, N.Y., during the tenure of a post-doctoral fellowship grant CAogr6I from the National Institute of Health, Viral Oncology Training Program to the Department of Pathology, New York University Medical Center, New York, N.Y., U.S.A.

\section{REFERENCES}

Barbera, A. J., Marchase, R. B. \& Roth, S. (1973). Adhesive recognition and retinotectal specificity. Proc. natn. Acad. Sci. U.S.A. 70, 2482-2486.

Carter, S. B. (1967a). Haptotactic islands: A method of confining single cells to study individual cell reactions and clone formation. Expl Cell Res. 48, 189-193.

CARTER, S. B. $(1967 b)$. Haptotaxis and the mechanism of cell motility. Nature, Lond. 213, 256-260.

Chambers, R. \& Fell, H. B. (I 93I). Micro-operations on cells in tissue culture. Proc. Roy. Soc. Lond. 109, 380-403.

Dulbecco, R. \& VoGT, M. (1954). Plaque formation and isolation of pure lines with poliomyelitis viruses. F. Expl Med. 99, I67-206.

DunN, G. A. \& Hesth, J. P. (I976). A new hypothesis of contact guidance in tissue cells. Expl Cell Res. ror, I-I4.

HARRIS, A. K. (1973). Behavior of cultured cells on substrata of variable adhesiveness. Expl Cell Res. 77, 285-297.

Harris, A. K. (1974). Contact inhibition of cell locomotion. In Cell Communication (ed. R. P. Cox), pp. 1 47-185. New York, London: John Wiley \& Sons.

KOREN, H. S., HANDWERgER, B. S. \& WUNDERLICH, J. R. (1975). Identification of macrophagelike characteristics in a cultured murine tumor line. F. Immunol. 114, 894-897.

Letourneau, P. C. (1975). Cell to substratum adhesion and guidance of axonal elongation. Devl Biol. 44, 92-101.

Maroudas, N. G. (1975). Adhesion and spreading of cells on charged surfaces. F. theor. Biol. 49, 417-424.

OldFibld, F. E., (1963). Orientation behaviour of chick leukocytes in tissue culture and their interaction with fibroblasts. Expl Cell Res. 30, 125-138.

RICH, A. (1978). Substratum and solution parameters of cell adhesion. Doctoral Thesis, University of North Carolina at Chapel Hill.

WILKINSON, P. C. (1977). Recognition of protein structure in leukocyte chemotaxis. Nature, Lond. 244, 5 I 2-5 I 3 .

(Received 7 October I980) 
